\title{
Effect of histone deacetylase inhibitor, trichostatin A, on cartilage regeneration from free perichondrial grafts in rabbits
}

\author{
Ning Zeng, Haiping Wang, Yi Xu, Yiping Wu and Min Wu* \\ Department of Plastics and Aesthetic Surgery, Tongji Hospital, Tongji Medical College, Huazhong University of Science and \\ Technology, Wuhan, Hubei Province, 430030, China
}

*For correspondence: Email: minwu1973@hotmail.com; Tel/Fax: 0086-27-83663568

Sent for review: 6 January 2017

Revised accepted: 16 May 2017

\begin{abstract}
Purpose: To evaluate the effect of histone deacetylase (HDAC) inhibitor, trichostatin $A$ (TCA), on cartilage regeneration in a rabbit perichondrial graft model.

Methods: Perichondrial grafts $(20 \times 20 \mathrm{~mm} 2)$ were derived from the ears of New Zealand rabbits and transplanted onto the paravertebral muscle of the face of each rabbit. The rabbits were separated into three groups: non-treated control group, vehicle-treated control group that received $0.3 \mathrm{~mL}$ of saline, and TCA-treated group administered $0.3 \mathrm{~mL}$ of TCA (500 $\mathrm{ng} / \mathrm{mL})$. Rabbits in all three groups were further divided into subgroups according to the duration of treatment after transplantation: 2, 4, 6, and 8 weeks $(n=12$ rabbits each). The effect of TCA on cartilage regeneration was determined histologically by evaluating the thickness of the cartilage plate in the grafted rabbits.

Results: TCA increased the amount of immature cartilage 4 and 6 weeks after perichondrial graft implantation. Mature cartilage was seen in the TCA-treated rabbits 8 weeks after transplantation. The thickness of the cartilage plate was significantly $(p<0.01)$ higher in TCA group $(905 \pm 36)$ than in either the non-treated (632 \pm 22$)$ or the vehicle-treated control $(639 \pm 22)$ group.

Conclusion: Treatment with trichostatin A, an HDAC inhibitor, enhances cartilage regeneration in rabbit recipients of a perichondrial graft. Furthermore, the findings of this study should be helpful in exploring the clinical use of trichostatin $A$.
\end{abstract}

Keywords: Histone deacetylase inhibitor, Perichondrial graft, TrichostatinA, Cartilage regeneration, Transplantation

Tropical Journal of Pharmaceutical Research is indexed by Science Citation Index (SciSearch), Scopus, International Pharmaceutical Abstract, Chemical Abstracts, Embase, Index Copernicus, EBSCO, African Index Medicus, JournalSeek, Journal Citation Reports/Science Edition, Directory of Open Access Journals (DOAJ), African Journal Online, Bioline International, Open-J-Gate and Pharmacy Abstracts

\section{INTRODUCTION}

The perichondrium is a connective tissue that supports the growth of cartilage. Several studies have shown that a perichondrial graft enhances cartilage repair and growth at anatomical locations including joints, the nasal septum, the larynx, and the ear $[1,2]$. The activity of chondrocytes is regulated by glycosaminoglycans and hyaluronic acid (HA), which enhance the secretion and synthesis of proteoglycans [3,4]. HA regenerates cartilage through mesenchymal signalling via fibrosis and scarring. The mechanisms underlying these processes include the inhibition of macrophage motility, the stimulation of lymphocyte migration and proliferation and granulocyte degranulation and phagocytosis [5].

Histones are alkaline proteins present in all eukaryotic cells. Histone deacetylase (HDAC) inhibitors preserve the acetylated state of histone 
and thereby alter gene expression; in turn, they thereby alter cellular migration, apoptosis, differentiation, and proliferation [6] as well as cellular functions such as fibrosis and angiogenesis $[7,8]$. The beneficial effects of HDAC inhibition in the therapeutic management of neurodegeneration, myelofibrosis, malignancy, and cystic fibrosis has been reported [9]. HDAC has also been implicated in cartilage regeneration and in chondrocyte hypertrophy [10]. Among the effects of the HDAC inhibitor trichostatin A (TCA) are accelerated embryonic development, increased stem cell differentiation, and potent anti-inflammatory and anti-cancer property activities [11-15]. TCA also enhances wound repair by increasing the acetylation of lysine in keratinocytes located at the wound site [16]. Based on these observations, the present study evaluated the chondrogenic effect of TCA in rabbit recipients of a perichondrial graft.

\section{EXPERIMENTAL}

\section{Animals}

The donor and recipient animals in this study were 2-month-old New Zealand rabbits 800 1200 g). They were kept under standard laboratory conditions at room temperature (20$25^{\circ} \mathrm{C}$ ) with a 12: 12-h light : dark cycle. The rabbits were allowed to acclimate to the lab for 10 days before the start of the experiment. The protocols used in this study were approved by the Animal Ethical Committee of Tongji Medical College, Huazhong University of Science and Technology, China (no. TJM/2015/ 14) and the given study followed the guidelines of Association for the Assessment and Accreditation of Laboratory Animal Care International (AAALAC) for experimentation and animal use [17].

\section{Graft collection and implantation}

The rabbits were separated into three groups of 12 each according to the different durations of treatment: 2, 4, 6 and 8 weeks. Surgery was performed in rabbits anaesthetised by an intramuscular injection of xylazine $(5 \mathrm{mg} / \mathrm{kg})$ and ketamine $(35 \mathrm{mg} / \mathrm{kg})$ followed by the prophylactic intramuscular injection of cefuroxime at a dose of $30 \mathrm{mg} / \mathrm{kg}$. The skin of the rabbits was sterilised before the operation, which began with a superficial incision of the ear skin. The skin was then withdrawn and a $20 \times 20 \mathrm{~mm}^{2}$ fragment of perichondrium was excised from its bed. The wound was sutured close using $5 / 0$ braided polyglactin. The graft was then sutured into place on the paravertebal muscle of the face of each rabbit using monofilament polypropylene $(6 / 0)$, ensuring that the graft was kept in a stretched position but without tension. The rabbits were separated into three groups: a non-treated control group, a vehicle-treated control group that received $0.3 \mathrm{~mL}$ of saline, and a TCA-treated group administered $0.3 \mathrm{~mL}$ of TCA $(500 \mathrm{ng} / \mathrm{mL})$. TCA and saline were injected beneath the perichondrial graft. Polyglactin sutures of $5 / 0$ were used to close the recipient site.

\section{Histopathological study}

Neochondrogenesis by the perichondrial graft was evaluated histologically 2, 4, 6 and 8 weeks after surgery. At each time point, rabbits from the different groups were euthanised, and tissue specimens were excised from the operative site. The specimens were fixed in $10 \%$ formalin, dehydrated in a graded series of ethanol, and paraffin-embedded. Tissue sections of $10 \mathrm{~mm}$ thickness, prepared using a microtome, were stained with haematoxylin and eosin (H \& E) and Masson's trichrome. Light microscopy $(400 \times)$ was used to evaluate the histology of the perichondrial graft according to the cellular content and cartilage thickness. The latter was measured at 10 different points using an ocular micrometer and the mean value was calculated. The pathologist evaluating the histology sections had no prior information about the treatment.

\section{Statistical analysis}

The results are expressed as mean \pm standard deviations $(n=12)$. The data were analysed by a one-way ANOVA followed by Dunnett's post-hoc test. $P<0.05$ was considered to indicate statistical significance.

\section{RESULTS}

\section{Effect of TCA on cartilage growth}

Neocartilage development was not observed in either the control or the vehicle-treated group after 2 post-operative weeks, whereas immature cartilage was detected at the perichondrial graft site in the TCA treated group. At 4 and 6 weeks after surgery, the neocartilage development in the TCA-treated group increased further. Signs of inflammation and infection were not seen in any of the groups. In the two control groups, the chondrocytes were smaller and pyknotic, lacked vacuoles, and were sparsely distributed, whereas the cells were spherical and contained cytoplasmic vacuoles in the TCA treated group (Figure 1).

After 8 weeks, mature chondrochytes were seen in all three groups, but the cartilage in both 
control groups was much thinner than the cartilage of the TCA group (Figure 2).

\section{Effect of TCA on cartilage thickness}

The thickness of the cartilage in the TCA-treated rabbits 8 weeks after perichondrial transplantation was $905 \mathrm{~mm}$, whereas it was 632 and $639 \mathrm{~mm}$ in the non-treated and vehicletreated control groups, respectively. The difference between the TCA group and both control groups was significant $(p<0.01)$, whereas the difference between the two controls was not.

\section{DISCUSSION}

Cartilage replacement is an essential aspect of orthopaedic, maxillofacial, and plastic surgery. The advantages of perichondrial grafting in the treatment of cartilage defects have been demonstrated in several experimental and clinical studies. The factors that promote cartilaginous differentiation from the perichondrium have also been examined [2]. The role of HDAC in cartilage regeneration and differentiation was previously described [18].
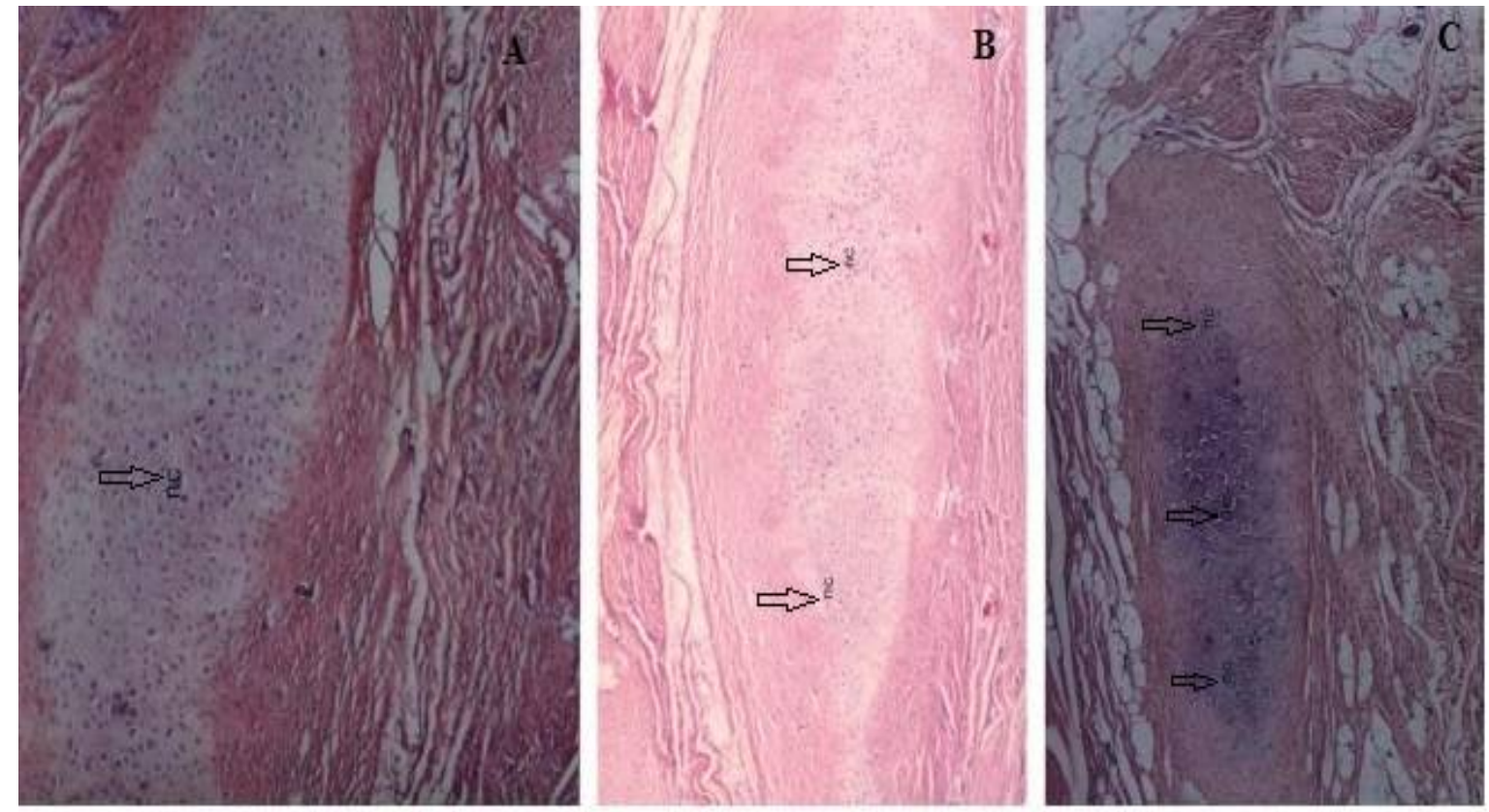

Figure 1: Effect of TCA on cartilage formation 4 weeks after the transplantation of a perichondrial graft $(H \& E$, $100 \times) . A=$ non-treated control group; $B=$ vehicle-treated control group; and $C=$ TCA-treated group
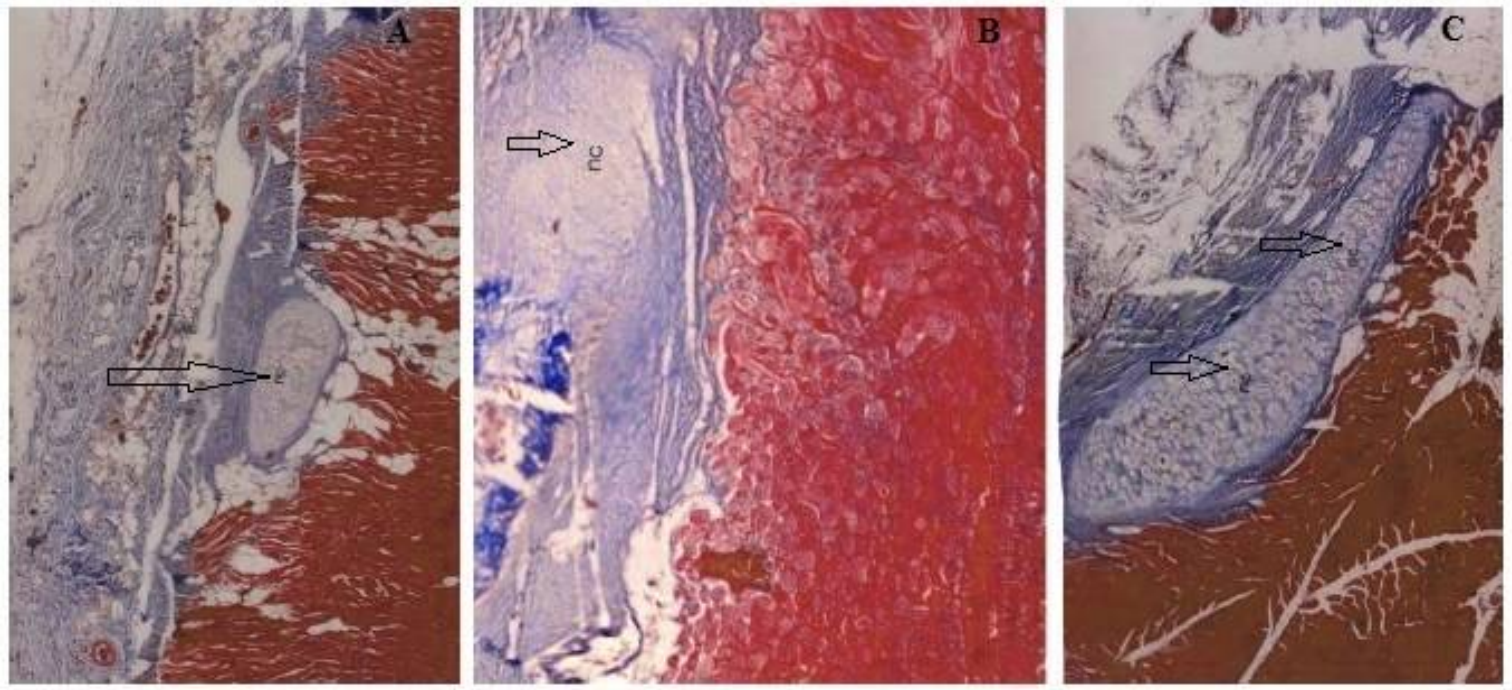

Figure 2: Effect of TCA on cartilage formation 8 weeks after transplantation of a perichondrial graft (Masson's trichrome, $100 \times$ ). $A=$ non-treated control group; $B=$ vehicle-treated control group, and $C=T C A$-treated group 
HDAC inhibitors alter extracellular matrix expression to promote cartilage growth by enhancing proteoglycan synthesis [19]. The HDAC inhibitor, TCA, enhances wound repair by increasing the acetylation of lysine in wound keratinocytes [16].TCA also accelerates embryonic development and stem cell differentiation in addition to possessing strong anti-inflammatory and anti-cancer properties [1115]. Among its mechanisms of action is a decrease in the expression of the metalloproteinase enzyme and the inhibition of cytokine stimulation. In our study, TCA was topically applied to the region of the perichondrial graft. TCA-stimulated neochondrogenesis was then determined by histological examination of cartilage tissue sections. Several compounds that promote chondrocyte differentiation and enhance graft thickness have been shown to stimulate cartilage regeneration in perichondrial grafts [20]. In this study, topical application of TCA significantly $(p<0.01)$ increased the thickness of the cartilage associated with the perichondrial graft compared to the control groups. Histological analysis of the TCA-treated graft showed increased neochondrogenesis.

Further investigations are needed to determine the optimal dose of TCA in cartilage regeneration and to examine possible side effects. Additional studies are also needed to assess the roles of the various factors that participate in modulating the TCA-induced cartilage regeneration process.

\section{CONCLUSION}

Topical application of the HDAC inhibitor TCA enhances chondrocyte proliferation and differentiation and, thus, neochondrogenesis from a perichondrial graft. Furthermore, the findings of this study will be useful in understanding the role of trichostatin $A$ in renal disease conditions.

\section{DECLARATIONS}

\section{Acknowledgement}

The authors thank the authorities of Tongji Hospital, Tongji Medical College, and Huazhong University of Science and Technology, China for providing the facilities for this study.

\section{Conflict of Interest}

No conflict of interest associated with this work.

\section{Contribution of Authors}

The authors declare that this work was done by the authors named in this article and all liabilities pertaining to claims relating to the content of this article will be borne by them.

\section{Open Access}

This is an Open Access article that uses a funding model which does not charge readers or their institutions for access and distributed under the terms of the Creative Commons Attribution License (http://creativecommons.org/licenses/by/ 4.0) and the Budapest Open Access Initiative (http://www.budapestopenaccessinitiative.org/rea d), which permit unrestricted use, distribution, and reproduction in any medium, provided the original work is properly credited.

\section{REFERENCES}

1. Homminga GN, Bulstra SK, Kuijer R, Linden AJV. Repair of sheep articular cartilage defects with a rabbit costal perichondrial graft. Acta Orthop Scand 1991; 62: 415418.

2. Upton J, Sohn SA, Glowacki J. Neocartilage derived from transplanted perichondrium: what is it? Plast Reconstr Surg 1981; 68: 166-172.

3. Armstrong $S$, Read $R$, Ghosh $P$. The effects of intraarticular hyaluronan on cartilage and subchondral bone changes in an ovine model of early osteoarthritis. $J$ Rheumatol 1994; 21: 680-688.

4. Bertolami CN, Gay T, Clark GT. Use of sodium hyaluronate in treating temporomandibular joint disorder: a randomized, double-blind, placebo-controlled clinical trial. J Oral Maxillofac Surg 1993; 51: 232-342.

5. Armstrong SE, Bell DR. Relationship between lymph and tissue hyaluronan in skin and skeletal muscle. Am J Physiol Heart Circ Physiol. 2002; 283: H2485-2494.

6. Lakshmaiah KC, Jacob LA, Aparna S, Lokanatha D, Saldanha SC. Epigenetic therapy of cancer with histone deacetylase inhibitors. J Cancer Res Ther. 2014; 10(3): 469-478.

7. Kim JH, Kim JH, Oh M, Yu YS, Kim KW, Kwon HJ. $\mathrm{N}$-hydroxy-7-(2-naphthylthio) heptanomide inhibits retinal and choroidal angiogenesis. Mol Pharm. 2009; 6: 513-519.

8. Rossig L, Li H, Fisslthaler B, Urbich C, Fleming I, Forstermann U, Zeiher AM, Dimmeler S. Inhibitors of histone deacetylation downregulate the expression of endothelial nitric oxide synthase and compromise endothelial cell function in vasorelaxation and angiogenesis. Circ Res. 2002; 91: 837-844.

9. Pang $M$, Zhuang S, Histone Deacetylase: A Potential Therapeutic Target for Fibrotic Disorders. J Pharmacol Exp Ther. 2010; 335(2): 266-272.

10. Pei M, Chen D, Li J, Wei L. Histone deacetylase 4 promotes TGF-beta1-induced synovium-derived stem cell chondrogenesis but inhibits chondrogenically 
differentiated stem cell hypertrophy. Differentiation. 2009; 78: 260-268.

11. Han RF, Li K, Yang ZS, Chen ZG, Yang WC. Trichostatin $A$ induces mesenchymal-like morphological change and gene expression but inhibits migration and colony formation in human cancer cells. Mol Med Rep 2014; 10(6): 3211-3216.

12. Grabiec AM, Tak PP, Reedquist KA. Targeting histone deacetylase activity in rheumatoid arthritis and asthma as prototypes of inflammatory disease: should we keep our HATs on? Arthritis Res. Ther. 2008; 10(5): 226.

13. Shao A, Wang Z, Wu H, Li Y, Tu S, Tang J, Zhao M, Zhang J, Hong $Y$, Dong $X$. Enhancement of autophagy by histone deacetylase inhibitor trichostatina ameliorates neuronal apoptosis after subarachnoid hemorrhage in rats. Mol. Neurobiol 2014; 53; 18.

14. Lim SY, Sivakumaran $P$, Crombie DE, Dusting GJ, Pébay $A$, Dilley RJ. Enhancing human cardiomyocyte differentiation from induced pluripotent stem cells with trichostatin A. Methods Mol Biol. 2016; 1357: 415-421.

15. Srirattana K, Ketudat-Cairns $M$, Nagai $T$, Kaneda $M$, Parnpai $R$. Effects of trichostatin $A$ on In vitro development and DNA methylation level of the satellite I region of swamp buffalo (Bubalusbubalis) cloned embryos. J Reprod Develop 2014; 60(5): 336-341.
16. Spallotta F, Cencioni C, Straino S, Sbardella G, Castellano S, Capogrossi MC, Martelli $F$ and Gaetano $C$, Enhancement of lysine acetylation accelerates wound repair. Commun Integr Biol. 2013; 6(5): e25466.

17. Guide for the Care and Use of Laboratory Animals: Eighth Edition Committee for the Update of the Guide for the Care and Use of Laboratory Animals; National Research Council. 2010; ISBN: 0-309-15401-4

18. Young $D A$, Lakey $R L$, Pennington CJ, Jones $D$, Kevorkian L, Edwards DR, Cawston TE, Clark IM: Histone deacetylase inhibitors modulate metalloproteinase gene expression in chondrocytes and block cartilage resorption. Arthritis Res Ther 2005; 7(3): R503-R512.

19. Blom $A B$, van Lent PL, Libregts S, Holthuysen $A E$, van der Kraan $P M$, van Rooijen $N$, van den Berg WB: Crucial role of macrophages in matrix metalloproteinase mediated cartilage destruction during experimental osteoarthritis: involvement of matrix metalloproteinase 3. Arthritis Rheum 2007; 56(1): 147-157.

20. Sommeling CE, Heyneman A, Hoeksema H, Verbelen J, Stillaert FB, Monstrey S. The use of platelet-rich plasma in plastic surgery: a systematic review. J PlastReconstrAesthet Surg. 2013; 66(3): 301-311. 